\title{
Mechatronics Education: Needs and Challenges
}

\author{
Gilberto Marzano \\ Rezekne Academy of Technologies \\ Rezekne, Latvia \\ gilberto.marzano@rta.lv
}

\author{
Andris Martinovs \\ Rezekne Academy of Technologies \\ Rezekne, Latvia \\ andris.martinovs@rta.lv
}

\author{
Svetlana Usca \\ Rezekne Academy of Technologies) \\ Rezekne, Latvia \\ svetlana.usca@rta.lv
}

\begin{abstract}
Mechatronics is a multidisciplinary branch that combines electronics, mechanics, and computer science. Due to the digital revolution, mechatronics is growing fast, rapidly spreading from manufacturing to many new sectors such as agriculture, healthcare, security, and transportation. As a consequence, mechatronics training courses are proliferating at the undergraduate and graduate levels. Nowadays, a considerable number of educational institutions, both academic and vocational, are offering mechatronics education, however their programs are not homogeneous and depend on teaching staff competence and available resources.

This paper presents NewMetro, an EU funded project that aims to develop an innovative European framework of competences for mechatronics education and an educational model able to address the needs of young people as well as adult workers undergoing requalification programs.

The philosophy of the project and the first activities carried out are illustrated and discussed.
\end{abstract}

Keywords-Education 4.0, Mechatronics, Mechatronics Education, Smart Learning Environments.

\section{INTRODUCTION}

The concept of mechatronics was introduced nearly 50 years ago as a consequence of the increasing use of computers for the control of mechanical processes and systems [1]. The term derives from the contraction of the words mechanical and electronic. It was coined in the early 1970s by Tetsuro Mori, an engineer from the Yaskawa Electric Corporation of Japan [2], to pinpoint synergetic systems composed of mechanical and electrical elements.

From the1980s, mechatronics grew as a multidisciplinary branch of engineering encompassing a mix of electronics, computing, telecommunications, and systems engineering. The basic components of mechatronics are sensors, microcontrollers, and actuators, as well as real-time software.

Over the last few years, interest in mechatronics has been reinvigorated due to the advances in sensing, communication, and computing. The extension of internet connectivity to physical devices has brought to the spread of the Internet of Things (IoT), a notion that encompasses everything is connected to the internet. Devices equipped with smart sensors can communicate with each other as well as with people who use smartphones or wearables [3], [4].
Many of the smart components associated with the IoT are mechatronic since the increasing complexity of the IoT applications entails a notable integration of the mechanical domain with the information technology and electronics domains.

Given that mechatronics is a multidiscipline and represents the combination of various systems, its scope is very vast and relates to multiple fields and domains [5], [6]:

- The Medical field: in areas such as surgery, radiology, and emergency medicine;

- Robotics Industry: for industrial robots and robotics systems;

- Automotive/Automobile engineering: in the design and manufacture of motorcycles, automobiles, and trucks that integrate mechanical, electrical, electronic, and software technologies as well as safety engineering;

- Research Organizations: with uses in instrumentation and sensors, microfluidic systems and MEMS (Micro-Electro-Mechanical Systems), and energy conversion;

- Mechanical Industry: with uses in designing, analyzing, manufacturing, and maintaining mechanical systems;

- Computer-Aided Design (CAD): with the use of computer systems to support and optimize mechanical design.

- Manufacturing Industry: in the production of industrial goods, machines, or tools;

- Mining: with uses in the extraction of valuable minerals or other geological materials from the earth;

- Inspection: for uses such as the inspection oil and gas pipelines via drones.

The increasingly numerous scope of applications of mechatronics brings us to the problem of what competencies are required to be able to work in so many different fields.

What are the competencies that should be included in an effective mechatronics curriculum?

Definitely, these competencies must relate to the six Key Enable Technologies (KETs) indicated, in 2014, by the European High-level Expert Group (HLG) in the Sta- 
tus Implementation Report of the second Key Enabling Technologies [7]. In this regard, the HLG observes that new technologies cannot be developed and brought to the market if the European work-force does not possess the necessary skills. In addition, the rapidly growing market in KETs related sectors requires an increasing number of professionals at all technical levels and from multiple disciplines. In this respect, the first HLG KET report noted that Europe is facing a damaging shortage of skilled labor qualified to master the multi-disciplinary nature of KETs.

Accordingly, a mechatronics curriculum should provide the basis for innovation in a wide range of sectors such as the automotive industry, food, chemicals, electronics, energy, pharmaceuticals, construction, and telecommunications.

Furthermore, this curriculum should be flexible and it should be continuously updated to keep abreast of continuing technological advances.

This paper presents NewMetro, an EU funded project that aims to develop an innovative European framework of competences for mechatronics education and an educational model able to address the needs of young people as well as adult workers undergoing requalification programs.

\section{The NewMetro project}

The structure of manuscripts:

The NEWMETRO project is a three-year Erasmus+ Sector Skills Alliance project that started in December 2018. It involves 11 partners from 7 European countries (Italy, Latvia, Austria, Germany, Poland Greece, and Spain).

This project is articulated around three different layers:

1. Educational and training layer, where partners design a model for mechatronics education, develop a curriculum, implement training activities, and run pilots. They involve enterprises with a view to individuating the mechatronics competency model, and evaluate the results of the pilot projects. They adopt a learning strategy that engages learners in work-based learning activities including ubiquitous learning, online collaborative learning, and digital social learning.

2. Inter-organizational layer, where partners, associated partners, and selected stakeholders cooperate in disseminating the project results. They bring about actions and organize events to show how remodeled mechatronics education can address the needs of Industry 4.0.

3. Policy-making layer, where the project results and recommendations are illustrated and discussed with policymakers and governmental authorities to frame new policies directed at sustaining continuous learning on KETs and offering workers flexible and advanced learning environments.

Currently, partners are engaged in the phase of Work package 1 "Participatory review and validation of already available training need analysis", led by The Rezekne Academy of Technologies. Their activities aim at:

- Understanding, sharing, and updating the current European surveys in the mechatronic field;

- Analyzing competence and related professional profiles;

- Providing a methodological framework to support and facilitate project implementation.

Partners should collect data from statistical sources, literature analysis, and structured interview. At this time, the literature analysis has already been carried out while interviews are still ongoing. Each partner is required to interview 50 key-persons involved in industrial activities (30 workers, 10 entrepreneurs or managers of enterprises, and10 policymakers) in order to create a comparative multidimensional matrix crossing the data.

The literature analysis has been performed on articles available in various academic databases (Scopus, Web of Science, Science Direct, and IEEE Xplore) and selected scientific journals. We adopted the PRISMA methodology [8].

Statistical data has only been collected from official sources and scientific surveys.

The following paragraphs report the preliminary results concerning the competence for a new mechatronics curriculum and the indications emerging for a teaching-learning environment.

\section{COMPETENCIES FOR MRCHATRONICS EDUCATION}

To design the competency model for mechatronics, we carefully analyzed the European multilingual classification, ESCO (European Skills, Competences, Qualifications, and Occupations) [9]. ESCO provides descriptions of 2,942 occupations and 13,485 skills linked to those occupations, translated into 27 languages (all the official languages of the EU plus Icelandic, Norwegian, and Arabic).

For mechatronics, ESCO indicates robotics as a key knowledge. Robotics is defined as a part of mechanical engineering, electrical engineering, and computer science that overlaps with mechatronics and automation engineering.

The skills and competence for a mechatronics engineer given by ESCO [10] are:

- maintain mechatronic equipment;

- test mechatronic units;

- install mechatronic equipment;

- develop mechatronic test procedures;

- simulate mechatronic design concepts;

- calibrate mechatronic instruments;

- assemble mechatronic units; 
- micro-mechatronic engineering.

From our analysis, the mechatronics competences should primarily encompass the following areas, since they are the most involved in Industry 4.0 and the ongoing technological revolution:

- Industrial design using advanced materials (e.g. biomaterials, metals, ceramics, polymers, powders);

- Microelectronics applied in the mechanical systems sector;

- Assembly line management (automation, supervision, measurement, data transmission and storage, etc.);

- Capabilities in the mechanical systems sector;

- LCA (Life Cycle Approaches) prognostics and environmental footprint evaluation;

- Integrating advanced systems design and manufacturing (modeling, simulation, virtual testing, data management, etc.);

- Advanced manufacturing systems (logistics management, cloud manufacturing, etc.);

- New equipment for telecare, telemedicine, and telerehabilitation based on intelligent mechanical objects;

- Domestic robots based on the Internet of Things paradigm;

- Applications in the scope of Smart and Connected Communities.

In some countries, standards for the profession of mechatronics engineer and mechatronics technician have been approved. They define knowledge, skills and competence required by these professionals. In Latvia, the first standard for the profession of mechatronics engineer was approved in 2002. [11]. In 2006, a new version that is currently being used was approved [12].

Focusing on the above areas, we create a preliminary list of skills and competencies based on the 2010 standard:

- designing algorithms for automation processes and developing tasks for machine design;

- using software for machine control;

- monitoring mechatronic machines;

- detecting failures, repairing, and maintaining automated machines;

- defining production technology plans;

- assessing production automation levels;

- choosing suitable materials for machine construction;

- developing software for automated controls;

- determining the lifetime of a mechatronic system;

- designing processes to ensure long-term quality operability of machines;

- assessing economically advantageous technical solu- tions;

- planning timely completion of tasks;

- managing staff;

- ensuring environmental, health, and safety requirements and standards.

We utilized the above lists in the structured interview to solicit feedback from stakeholders.

\section{A SMART TEACHING LEARNING ENVIRONMENT}

Our preliminary analysis confirmed that, in order to create a robust educational framework for mechatronics, a smart teaching-learning environment should be implemented.

The adjective 'smart' is very popular nowadays. In everyday usage, it refers to an action or decision that involved careful planning, cleverness, innovation, and/ or a desirable outcome [13]. In the field of technology, instead, it is a label used in a wide variety of ways to underlie the combined use of intelligent devices, advanced analytics, and artificial intelligence algorithms (Fig. 1).

Lately, smart has also been associated with educational practice: smart schools, smart classrooms, and smart learning technologies are spawning seemingly everywhere. In the field of education, SMART is also an acronym for Sensitive, Manageable, Adaptable, Responsive, and Timely, and refers to interactive technology that has a flexible and tailored approach to meet diverse individual learning needs.

A smart learning environment for mechatronics (Fig. 1) should encompass intelligent tutoring, adaptive learning, technology-enhanced learning, mobile learning, and context-aware ubiquitous learning [14], [15]. Sensing technologies, as well as virtual reality, should enable learners to access learning resources that simulate real situations. Moreover, supportive tools should be implemented to provide them with contextual guidance and hints.

In essence, then, the smart learning environment for mechatronics education should be a technology-enhanced teaching-learning system that simulates the real-world, allows access to different types of resources, provides collaborative functions, and can be easily adapted for work-based learning.

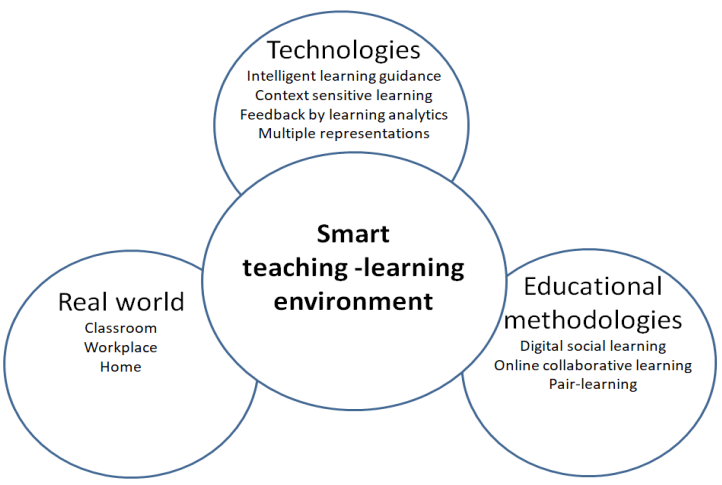

Fig. 1. Components of a smart learning environments 
The primary criteria identified in the literature for smart learning environments are:

1. Context-sensitiveness; that is, learning activities are lead according to the real-world environment in which the learner is (e.g., classroom, workplace, home);

2. Adaptive support; this is, learners are led by immediate analyses of their needs from various different perspectives (e.g., learning performance, learning behaviors, profiles, personal factors) as well as the online and real-world contexts in which they are situated;

3. Flexible user interface; this is, information is presented that meets the learner's personal factors (e.g. learning styles and preferences) and their learning status (e.g. learning performance).

\section{CONCLUSION}

It has been observed that: The collaboration between science and technology, and the mechatronic integration of technology make possible the biggest and fastest evolution of humanity in the history of technology [16].

Mechatronics creates new complex products using and integrating the discoveries of other disciplines. As a consequence, mechatronics can be found embedded in most of the new advanced products today. Appropriately, integration should also be a fundamental characteristic of mechatronics education.

It should not only encompass the skills and competencies of a mechanical engineer, a computer engineer, and an electrical engineer, but also adopt a novel educational model to prepare the students to meet the new industrial and societal needs.

Traditional courses in engineering as well as the mechatronic courses currently on offer are compartmentalized and taught by an individual instructor. In the near future, this approach will be inadequate since the solution of real problems invariably requires integrating different subjects and disciplines, both technical and non-technical [17].

This is very challenging. Indeed, it immediately appears evident that the current distinct engineering modules should be revised and improved in order to bring about a seamless .transition from university to industry and society.

The NEW METRO project tackles this challenge. It is still in its early stages, but the crucial role of the teaching-learning environment has appeared evident.

In this article, we have highlighted the smart teaching-learning environment that should support the new mechatronics curriculum, ensuring two primary needs. Firstly, allowing the continuous adaptation of the technological components and the learning content. Secondly, fostering the minds-on and hands-on capacities of learners through teaching-learning methodologies such as Digital Social Learning, Pair-learning, and Online Collaborative Learning.

\section{REFERENCES}

[1] D. Bradley, D. W. Russell, I. Ferguson, J. Isaacs, A. MacLeod and R. White, "The Internet of Things-The future or the end of mechatronics". Mechatronics, 27, pp. 57-74, 2015.

[2] D. Bradley, D. W. Russell, Mechatronics in action, Springer, 2010.

[3] A. Al-Fuqaha, M. Guizani, M. Mohammadi, M. Aledhari and M. Ayyash, "Internet of things: A survey on enabling technologies, protocols, and applications", IEEE communications surveys \& tutorials, 17(4), pp. 2347-2376, 2015.

[4] P. P. Ray, P. P. “A survey on Internet of Things architectures", Journal of King Saud University-Computer and Information Sciences, 30(3), pp. 291-319, 2018.

[5] S. E. Lyshevski, Electromechanical systems, electric machines, and applied mechatronics, CRC press, 2018.

[6] O. O. V. Villegas, M. Nandayapa and I. Soto (Eds.). Advanced Topics on Computer Vision, Control and Robotics in Mechatronics, Springer, 2018.

[7] Expert Group on Key Enabling Technologies (KETs), Status Implementation Report July 2013, European Commission, 26/11/2014. Available at: https://ec.europa.eu/growth/content/status-implementation-report- $\% \mathrm{E} 2 \% 80 \% 93$-second-high-level-expert-group-key-enabling-technologies-kets en; last accessed 1.04.2019.

[8] D. Moher, A. Liberati, J. Tetzlaff, D. G. Altman, “The PRISMA Group (2009) Preferred Reporting Items for Systematic Reviews and Meta-Analyses: The PRISMA Statement”, PLoS Med 6(7): e1000097, 2009. Available at: https://doi.org/10.1371/journal.pmed.1000097; last accessed 1.04.2019.

[9] ESCO (European Skills/Competence, qualification and Occupations), https://ec.europa.eu/esco/portal/; last accessed 01.04.2019.

[10] ESCO Portal, Mechatronics. Available at: https://ec.europa.eu/ esco/portal/search?term=mechatronics; last accessed 01.04.2019.

[11] Ministry of Education and Science, "PROFESIJAS STANDARTS.", n. 405, July 2002. Available at: https://visc.gov.lv/profizglitiba/dokumenti/standarti/ps0097.pdf; last accessed 01.04.2019.

[12] Government cabinet, "2.pielikums Ministru kabineta”, n. 461, May 2000. Available at: http://www.lm.gov.lv/upload/darba devejiem/profesiju standarti 0811.pdf; last accessed 01.04.2019.

[13] J. M. Spector (Ed.), The SAGE encyclopedia of educational technology, Sage Publications, 2015.

[14] R. Huang, J.Yang and Y. Hu, "From Digital to Smart: The Evolution and Trends of Learning Environment", Open Education Research, 1,pp. 75-84, 2012.

[15] G. J. Hwang, "Definition, framework and research issues of smart learning environments-a context-aware ubiquitous learning perspective", Smart Learning Environments, $1(1), 4,2014$.

[16] I. Vlaşin, S. Greta, L. Dache and V. Mătieş, "Integrative platform based on the mechatronics model for educational technologies focused on competence" In IOP Conference Series: Materials Science and Engineering (147)1, IOP Publishing, August 2016. Available at: https:// iopscience.iop.org/article/10.1088/1757-899X/147/1/012054/pdf; last accessed 01.04.2019.

[17] Y. Wang, Y. Zhu, Y. Yu, X. Zhang, and C. Xie, C, "Simulating Industry: A Holistic Approach for Bridging the Gap between Engineering Education and Industry. Part II: Practice in Mechatronics Engineering", International Journal of Engineering Education, 31(1), pp. 174180,2015 . 